\title{
The Pursuit of the Source, or The Inevitability of Death'
}

1 Mats Persson²

PhD, Faculty of Business, Languages, and Social Sciences, Østfold University College, Norway

I Jan Ch. Karlsson

Professor Emeritus, Working Life Science, Karlstad University, Sweden

\begin{abstract}
The purpose of this article is to apply the method of the genre of studying chains of references to an instance of a secondary source of the contested concept of 'resistance to change' back to the primary source and thereby exercise criticism of the sources. This includes discussing whether the theory itself is empirically sustainable or sufficiently scientifically grounded. In the article, we adopt a theoretical lens of Critical Realist Discourse Analysis, mainly because it is sensitive to the importance of the influence of nondiscursive social positions on discourses. The primary source of the chain of theories of resistance to change turns out to be Kübler-Ross's model of stages of dying patients' reactions to their immanent death. We find that the model is systematically misinterpreted to fit the empirically false idea of resistance to change of the ideological discourses of management research.
\end{abstract}

\section{KEYWORDS}

Organizational change / reference / resistance

\begin{abstract}
here is a social science genre of studying chains of references and changes in argumentation in these chains (e.g., Morrisey 2002; Rekdal 2014b; Wright \& Armstrong 2008). Let us call it the reference pursuit genre. We understand genre as 'a relatively stable set of conventions that is associated with, and partly enacts, a socially ratified type of activity' (Fairclough 1992, p. 126), in this case within social science. The kernel of the investigations is how authors can refer to other scholars' empirical descriptions or theories at several removes and how these descriptions or theories are thereby modified over time. In this tradition, the distinction between primary and secondary sources is important. The primary source is 'a firsthand report of observations or research results written by the individual(s) who actually conducted the research and made the observations'; the secondary source is 'a description or summary of another person's work. A secondary source is written by someone who did not participate in the research or observations being discussed' (Gravetter \& Forzano 2012, p. 48, cit. in Rekdal 2014a, p. 584). Together, they make up the chain of sources or references: from a series of second sources back to the primary source.
\end{abstract}

\footnotetext{
${ }^{1}$ You can find this text and its DOI at https://tidsskrift.dk/njwls/index.

${ }^{2}$ Corresponding author: mats.persson@hiof.no.
} 
We adhere to this genre in following a chain of sources in organization theory. In the genre, the topic of the studies is usually an empirical pattern, for example, expatriate failure rates (Hatzing 2002), the role of culture in urban regeneration (Campbell et al. 2017) and the iron content of spinach (Rekdal 2014a). However, we put less stress on empirical patterns and more on theories and theoretical changes. Of course, we also discuss empirical patterns, but the main emphasis is on theoretical issues. It belongs to the methodology in this type of investigation to take a specific secondary source as a point of departure and follow the chain of references until the primary source is revealed. The variations in empirical descriptions and theoretical argumentations can then be scrutinized through critique of the sources. We follow this methodology. As our field of research is organizations and working life, we have not only chosen as our topic an extremely common but also contested concept, namely 'resistance to change'. It is easy to find it depicted as a fruitful concept for not only both understanding employees' actions and giving advice on management practice in connection with organizational change (Oreg 2003; Pardo del Val \& Fuentes 2003; Yilmaz \& Kiliçoğlu 2013), but also subjected to criticism (e.g., Choi \& Myungweon Ruona 2010; Dent \& Galloway Goldberg 1999; Huzell 2005: 31-35). Texts that describe an empirical, theoretical or methodological development made by the authors themselves are thus primary sources, while texts that describe a corresponding development made by others are secondary sources. The second step is to evaluate the content of the concept we started from in our pursuit of the source in relation to the following second sources and to the primary source - in other words, exercising criticism of the sources.

The purpose of this article is, then, to apply the method of the genre of studying chains of references to an instance of a secondary source of the contested concept of resistance to change back to the primary source and thereby exercise criticism of the sources. This includes discussing whether the theory itself is empirically sustainable or sufficiently scientifically grounded. In the article, we adopt a theoretical lens of discourse analysis. Now, there are several varieties of discourse theory and our choice among them is grounded in the need to be able to analyze not only discourses' influence on other discourses, but also how social agents and structures can exercise such influence. In other words, we have to avoid the ontological idea that the social world is exclusively made up of discourses (Fairclough 2003, p. 2). Such a view would hamper our analysis considerably. Instead, we regard discourses as only one part of social life, which also contains social phenomena (Fairclough et al. 2002) as well as social and discursive aspects of artifacts and natural phenomena (Fleetwood 2004; 2005; Karlsson \& Bergman 2017, Ch. 1). We therefore use 'Critical Discourse Analysis', especially in the form of 'Realist Discourse Analysis' (Newman 2020) and agree with Fairclough (2005, p. 915) that 'a version of critical discourse analysis based on a critical realist social ontology is potentially of greater value to organization studies' than discourse analysis that commits to postmodernism and extreme versions of social constructivism.

In line with this position, we define discourse as 'semiotic ways of construing aspects of the world (physical, social or mental) which can generally be identified with different positions or perspectives of different groups of social actors' (Fairclough 2009, p. 163). One example is the theory that employees go through a series of phases when confronted by changes in organizations, and some of those phases involve resistance to change. This is a discourse based on a management ideology of resistance to change in the tradition of Coch and French (1948), Zander (1950) and Lewin (1951). Ideology can be defined 
as 'a coherent and relatively stable set of beliefs or values' (Wodak \& Meyer 2009, p. 8, emphasis removed), and is the 'prime means of manufacturing consent' (Fairclough 1989 , p. 4). Referring is a form of intertextuality where 'texts are linked to other texts' (Wodak \& Meyer 2009, p. 90) and when authors choose to refer to a specific text, they are 'seeking to universalize particular meanings in the service of achieving and maintaining dominance, and this is ideological work' (Fairclough 2003, p. 58). Referring to specific theories in texts is therefore (also) a way of seeking hegemony in a contested terrain of different organization theories struggling for dominance.

In doing so, theories are not only reproduced but also redefined and transformed into something different from the original theory. This transformation cannot only be a consequence of theory development but also of poor reference practice. In the latter case, theories stand the chance of being recontextualized into a new context (Wodak \& Meyer 2009, p. 90) that might render the theory in question empirically invalid. In practice, this means that a theory is used within a different context than the one in which it was originally developed. Although the theory may not be empirically valid, it does not preclude using it to secure or reinforce its discursive position. How references are used is not only a matter of strengthening one's argument or an ethical concern - it is also a discursive positioning of specific theoretical perspectives in a wider discourse of organizational change where the concept of 'resistance to change' seeks a hegemonic position.

The article is structured in this way: In the next section, we state our point of departure in a theory of resistance to change as offered in a widely disseminated elementary university textbook in organization theory. We start by noting to whom the authors refer. Then, we search out that text and note the source that this author in turn refers to. We carry on in the same way until we can get no further. When we have found the primary source through this series of links, we make it the object of criticism of the source and in the penultimate section we deliver criticism of the way sources using the concept of resistance to change have referred to the primary source. Finally, we summarize our pursuit of the source and the criticisms we have delivered.

\section{The first link (Jacobsen and Thorsvik)}

We take our point of departure in the theory that employees go through a series of phases when confronted by changes in organizations. The text is taken from the most recent edition of the textbook Hvordan organisasjoner fungerer [How organizations work] by Dag Ingvar Jacobsen and Jan Thorsvik (2019). This is a popular textbook in organization theory in the whole of Scandinavia. We have no grounds for believing that it is either more or less accurate in its citation practice than other books.

The text is part of a section with the heading 'Resistance to change', to be found on p. 378:

People confronted with changes they are not prepared for, go through typical phases in their reaction (Irgens 2011). First, there is a phase of surprise - they are shocked. Is this possible? What do these changes mean for us as a group and for me personally? Then comes the phase of denial. No, it is not possible. It is just not on. They will not manage it. Someone will stop the whole process. The next phase is depression in which you feel powerless and many simply opt out of the whole process. There is no point anyway. After a 
while, a new phase emerges characterized by reluctant acceptance. There is no way around this; we will just have to do it. Next is the trial phase in which new ways of organizing operations and new working methods are tried out. This is followed by the consolidation phase in which changes in practice that function are consolidated into structures and processes. The last phase is adjustment in which the changes are accepted.

The text is formulated in such a way that it can easily be interpreted as meaning that people faced with sudden changes always go through particular 'typical phases in their reaction'. The statement is discursively ideological in that it has no reservations; it is universalizing through being portrayed as being valid always and for everyone. Then, the different phases are presented with no further explanation of what they consist of or how they are connected. The use of the present tense makes it natural to interpret the text as an empirical generalization of the way in which people actually react (Danermark et al. 2019, p. 99): 'Knowledge of a limited amount of events is extrapolated to, and is assumed to be valid for, a larger population. Generalizations can be made to larger populations over time, and to events in various sociocultural contexts'. In other words, the text is formulated in such a way that it can be perceived as a general truth that we all go through the phases mechanically in sequential order, thereby establishing hegemony for this theory of phases involving resistance to change.

The reference in the quote is to the book Dynamiske og laerende organisasjoner [Dynamic and learning organizations] by Eirik Irgens - so we go looking for it.

\section{The second link (Irgens)}

On the back cover of Dynamiske og laerende organisasjoner (Irgens 2011), we read that the book concerns 'the challenges we face when leading, developing and working in a working life characterized by insecurity and changes'. We find our way to the theory to which Jacobsen and Thorsvik refer. Under the heading 'Resistance to change', Irgens points out that this is taken from John Hayes (2002). Irgens's text is accompanied by a figure illustrating the various phases mentioned, which he comments on as follows (Irgens 2011, p. 35-36):

Hayes (2002) asserts that we go through some typical phases of reaction when we are confronted by changes we are not prepared for [...]. First, there is a phase of strong surprise ("shock"), which again can lead to us becoming more or less paralyzed. Typically, this phase goes over into a phase of denial ("this will pass") where individuals do what they can to sabotage the change process. The next phase is depression. Typically, the situation will be experienced as out of one's control, and some will withdraw and "opt out". The next phase is characterized by a reluctant acceptance: There is no way around it, the process of change will not pass, but we do not like it. The trial phase is when we begin to try out some of the new working methods and organizational forms, and in the consolidation phase, we are focused on learning the new routines and working methods so that we can master them. The final phase, according to Hayes, is adjustment: We have accepted that things are changing and are working with the changes rather than against them. 
Irgens presents a diagram in which the various phases are connected to two concepts along two axes. The horizontal X-axis represents 'time', while the vertical Y-axis represents 'emotional response'. Irgens does not discuss the layout of the graph or define the term 'emotional response', but it shows the various levels of emotional response over time: It is weakest in the initial and final phases, that is, 'shock' and 'adjustment', respectively, while it is strongest in the 'reluctant acceptance' phase. This gives the graph the form of an inverted U-curve with 'reluctant acceptance' at the top, and 'shock' and 'adjustment' at either end of the scale.

He makes a caveat by saying that Hayes 'asserts' that we go through some typical phases of reaction when confronted with changes we are not prepared for. Thus, it is made clear that Hayes, not Irgens, is behind the model and that Irgens is inviting discussion of Hayes's model. Irgens uses the present tense just as Jacobsen and Thorsvik do when describing the development of the phases, but, unlike them, he allows for nuances in the theory (Irgens 2011, p. 36):

Hayes's explanation is good in the sense that it portrays a pattern that is recognizable and easy to grasp. On the other hand, there is a danger that such explanations conceal the fact that change processes are not predetermined and can develop very differently from person to person and from process to process.

Precisely the fact that change processes are not predetermined but can vary between people and processes allows other interpretations and understandings of the model. This is an important criticism of the source by Irgens that Jacobsen and Thorsvik have passed over. Irgens's discourse is thereby more careful than that of Jacobsen and Thorsvik - it does not seek hegemony in the same strong way.

Irgens does not present any source reference for the figure itself, which makes it unclear whether it is taken from Hayes (2002), is of his own making or taken from another source. We will therefore go in pursuit of the source and see what Hayes writes about resistance to change.

\section{The third link (Hayes)}

We have now come to the third link in our pursuit of the source: Irgens's reference to Hayes (2002) and his book The Theory and Practice of Change Management. On pp. 151-152, we are presented with the particular phases employees go through when there are organizational changes. In a section with the heading 'The stages of psychological reaction', Hayes describes the phases of 'Shock', 'Denial', 'Depression', 'Letting go, acceptance of reality', 'Testing', 'Consolidation' and 'Internalization, reflection and learning'. There is a clear correspondence between the phases in the respective models of Hayes (2002) and Irgens (2011). Hayes's descriptions of the various phases correspond so closely to Irgens's text that we choose not to reproduce them here. The difference is that Hayes describes how the 'Mood' changes in the course of time and how this relates to the various phases. There is no corresponding description in Irgens's text of how the phases are connected to emotional response over time. There is a difference in another respect too, namely in the graphs depicting the various phases. Hayes's diagram has the shape of a wave, where the term on the X-axis corresponds to Irgens's diagram ('Time'), 
but the 'Mood' of the Y-axis is not the same as 'Emotional response'. What is more, the shape of the graphs is, as we have mentioned, quite different: In Hayes's diagram, 'Mood' is at its weakest in the second trough that represents the phase 'Letting go, acceptance of reality', while in Irgens's diagram, it is 'Reluctant acceptance' that is the strongest emotional response. This should have to do with the definition of the terms but there is no such definition in either source. Furthermore, in Hayes's figure, the phase 'Letting go, acceptance of reality' is at roughly the same level as the first trough denoting 'Shock', while Irgens's figure has the same phases (Shock and Reluctant acceptance) at opposite ends on the scale of emotional response. We have been in touch with Eirik Irgens (personal communication), who explained that the figure is his own construction, based on Hayes's text rather than his diagram. The term 'Emotional response' is used on the Y-axis, he pointed out, because Hayes writes more often about reactions, responses and adjustment than about mood. At the same time, we should remember that, since the terms used on the Y-axis differ without us knowing how they are defined, the two figures are not easily comparable. Irgens's figure is an instance of intertextuality that, according to Fairclough (1992, p. 102), 'points to the productivity of texts, to how texts can transform prior texts and restructure existing conventions (genres, discourses) to generate new ones'. Although the figure Irgens presents invites to a discussion on the heterogeneity of figures used in the theory that employees go through a series of phases when confronted by changes in organizations, the management ideology of resistance to change is a mutual discourse in the texts. It thereby turns out that despite Irgens's carefulness, his discourse seeks hegemony through referring to Hayes's (2002) model without mentioning that he has transformed it according to his own interpretation of Hayes's discourse.

Hayes states that his model is taken from another text (2002, p. 151): 'The model presented below has been developed by John Hayes and Peter Hyde from an earlier version which originally appeared in Transition: Understanding and Managing Personal Change by John Adams, John Hayes and Barrie Hopson (1976)'. Oddly enough, there is no reference to Hayes and Hyde's further development. In order to progress in our pursuit of the source, we must instead go to the work by Adams et al. (1976) mentioned here. Before we continue to the next link in the chain, however, we would like to point out that Irgens (2011) referred to Hayes in the first edition of The Theory and Practice of Change Management from 2002. However, it now appears that Hayes has published several editions since then, in 2006, 2010, 2014 and 2018. From the fourth edition (2014) onwards, we are told something that was missing in the first edition - that is, where the diagram came from. Hayes writes (2018, p. 270): The diagram 'has been developed by Hayes and Hyde (1996) from an earlier version that originally appeared in Transitions: Understanding and Managing Personal Change by Adams, Hayes and Hopson (1976)'. So, here is a reference we have not seen before. It refers to an unpublished manual entitled 'Transition Workshops' from a consulting company (Hayes \& Hyde 1996). Another issue that is worth noticing is that in this version of the graph the term on the Y-axis has been altered from 'Mood' (2002) to 'Self-efficacy' (2018). We are not offered any explanation for why the authors made this change in terminology.

Since we have been unable to get hold of Hayes and Hyde's unpublished manual, we return to our pursuit and the next link in the chain, namely the book that Hayes refers to: Transition: Understanding and Managing Personal Change by Adams et al. (1976).

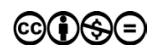




\section{The fourth link (Hopson and Adams)}

The book we just mentioned is an anthology about change in general, not necessarily organizational change or the management of change. Referring to theories of change in general in the context of organizational change and change management is an example of recontextualization (Wodak \& Meyer 2009, p. 90). In their introduction, the editors write that the book 'investigates the processes of individual movement from one relatively stable state to another' (Adams et al. 1976, p. ix). Once again, we find the now familiar diagram and the description of the phases in a chapter called 'Towards an understanding of transition: Defining some boundaries of transition dynamics' by Hopson and Adams (1976). We notice that Hayes is not a co-author of this chapter.

Introducing the theory of the change phases in a section called 'Is there a general model of transition?', the authors (Hopson \& Adams 1976, p. 8) admit that 'We were heavily influenced in our thinking by Adams (1969)'. This is a reference to an unpublished doctoral thesis - and this is the first time we come across a reference to empirical support for the theory that employees go through particular phases in connection with change. According to the authors, Adams carried out a study in which he interviewed 33 students and, based on this, developed a model that 'described their passage, psychologically, through the program, from being primarily self-oriented to involvementoriented to instrumentality-oriented' (Hopson \& Adams 1976, p. 9). Adams's thesis has not been available to us, so we have to simply rely on what the authors of this secondary source say. At the same time, there is a good deal of uncertainty involved in citing unpublished sources as empirical evidence. It makes it difficult, if not impossible, for a reader to find the source, to use Rekdal's (2014a, p. 571) words.

We see also that Adams describes the phases in a different way to Hopson and Adams (1976). So, from where do the latter have it? The answer to this question is found a little later in the text (p. 9): 'As we began to discover other work on different transitions, increasingly a general picture began to emerge'. Thus, they describe the phases as 'Immobilization', 'Minimization', 'Depression', 'Acceptance of reality', 'Letting go', 'Testing', 'Search for meaning' and 'Internalization'. They also describe how they have arrived at these phases (p. 9):

The identification of these seven phases has come about through content analysis of reports from over 100 people who have attended transition workshops for the purpose of understanding and learning to cope more effectively with transitions they were experiencing and through extending the findings reported above.

This is, in other words, the empirical basis for the general theory that we go through specific phases in connection with change. There are no references that make it possible to examine how they have arrived at these phases. All we know is that they are relying on two unpublished texts: Adams's doctoral thesis and an analysis of consultant reports from workshops. Still, this is discursively ideological work through referring to empirical evidence - even if it is not possible to consult the sources. As far as the figure is concerned, they present it as their own construction (p. 12): 'The level of one's selfesteem varies across these phases and appears to follow a predictable path. Identifying the seven phases along such a self-esteem curve often gives one a better understanding of the nature of the transition cycle'. The curve mentioned resembles the wave form that 
Hayes presented in his diagram. What Jacobsen and Thorsvik only implied in their presentation, is expressed explicitly here: The figure constitutes a deterministic, sequential path, impressing it on the reader as hegemonic knowledge.

If we compare Hayes's (2018) diagram with that of Hopson and Adams (1976), we find a couple of differences. One is that the term on the Y-axis is not 'self-efficacy', but 'self-esteem'. Also, the first phase is called 'Immobilization' rather than 'Shock', while the second phase is called 'Minimization' rather than 'Denial' and the sixth phase 'Search for meaning' rather than 'Consolidation'. However, the content descriptions are the same, that is, the differences in terms cover the same concepts.

The next link is really Adams's doctoral thesis, which, however, is not available. Does this mean that we can go no further in our pursuit of the source? No, perhaps not, since Hopson and Adams introduce a new source that turns out to be interesting. It concerns Elisabeth Kübler-Ross and her study of how terminally ill patients go through particular phases in dealing with their grief. In this way, they indicate what for us will be the fifth link (Hopson \& Adams 1976, p. 12):

\footnotetext{
More recently, Elisabeth Kübler-Ross and those who joined her death and dying seminars have also charted a very similar curve of the reaction cycle people go through upon learning they are terminally ill - the ultimate transition.
}

They are referring here to a figure by Mwalimu Imara (1975). As they point out, it is very similar to their own figure. Imara has written a chapter in an anthology on death, edited by Kübler-Ross. This is another example of recontextualization where the context shifts from students to terminally ill patients, and it is our point of departure in the next section.

\section{The fifth link (Kübler-Ross and Imara)}

We have now come so far in our study of linked discourses that we can see a straight line of descent from Jacobsen and Thorsvik (2019) to Kübler-Ross (2006 [1969]) and Imara (1975) via Hopson and Adams (1976), Irgens (2011) and Hayes (2002; 2018). The phases depicted in their diagrams are largely similar. However, there is no direct reference by Hopson and Adams to Kübler-Ross or Imara or a suggestion that they are building on these theories about reactions to facing death. What they say is that KüblerRoss established roughly the same model at roughly the same time (1976, p. 4):

Kübler-Ross (1969) has a systematic model to account for people dealing with the fact of their own approaching deaths, and the reactions of their relatives and friends to this. Adams (1969) discovered that applied behavioural science professionals in training pass through a number of identifiable stages.

Their main reference, however, is to Imara (1975) and a chapter entitled 'Death as the last stage of growth' in the book Death: The Final Stage of Growth, edited by Kübler-Ross. We notice that although Hopson and Adams mention Kübler-Ross, the reference is to a diagram and a chapter by Imara, not to Kübler-Ross herself. She is otherwise most famous for her book On Death and Dying (2009 [1969]). We will return to that book shortly. 
In Imara's figure, as it is presented in the chapter by Hopson and Adams, the Y-axis is called 'MOOD Healthy (stability)', while the X-axis does not have a heading. The original diagram in Imara's chapter, on the other hand, has neither an X-axis nor a Y-axis. However, apart from minor differences in layout they appear to be the same, and the phases are 'Denial (shock)', 'Anger (emotion)', 'Bargaining', 'Preparatory depression' and 'Acceptance' (Imara 1975, p. 161). However, Imara's theory is discursively transformed without Hopson and Adams telling their readers that that is the case. They write as if they simply reproduce Imara's figure while also referring to Kübler-Ross.

In her book On Death and Dying, originally published in 1969, Kübler-Ross presents the various phases of patients' processing diagnoses that mean they are dying. There is a figure with the heading " "Stages" of Dying' (Figure 1), picturing the phases. We note that the figure is not constructed as a diagram with a curve (as all the previously mentioned figures are) and that 'Shock' is outside the division into stages, which starts with 'Denial'. In addition, Kübler-Ross says that, parallel with the various phases from 'Anger' onwards, there is also 'Hope'. This element is missing from the previous figures depicting change, but it is one that Kübler-Ross strongly emphasizes. She writes (2009, p. 214): 'No matter the stage of illness or coping mechanisms used, all our patients maintained some form of hope until the last moment'. The last designation 'Decathexis', which seems to lie outside the five phases that end with the patient's death, is not included in the previous figures either. So, we have found in Kübler-Ross's model the original source of the stages that employees are expected to go through in connection with organizational changes.

Figure I 'Stages' of dying.

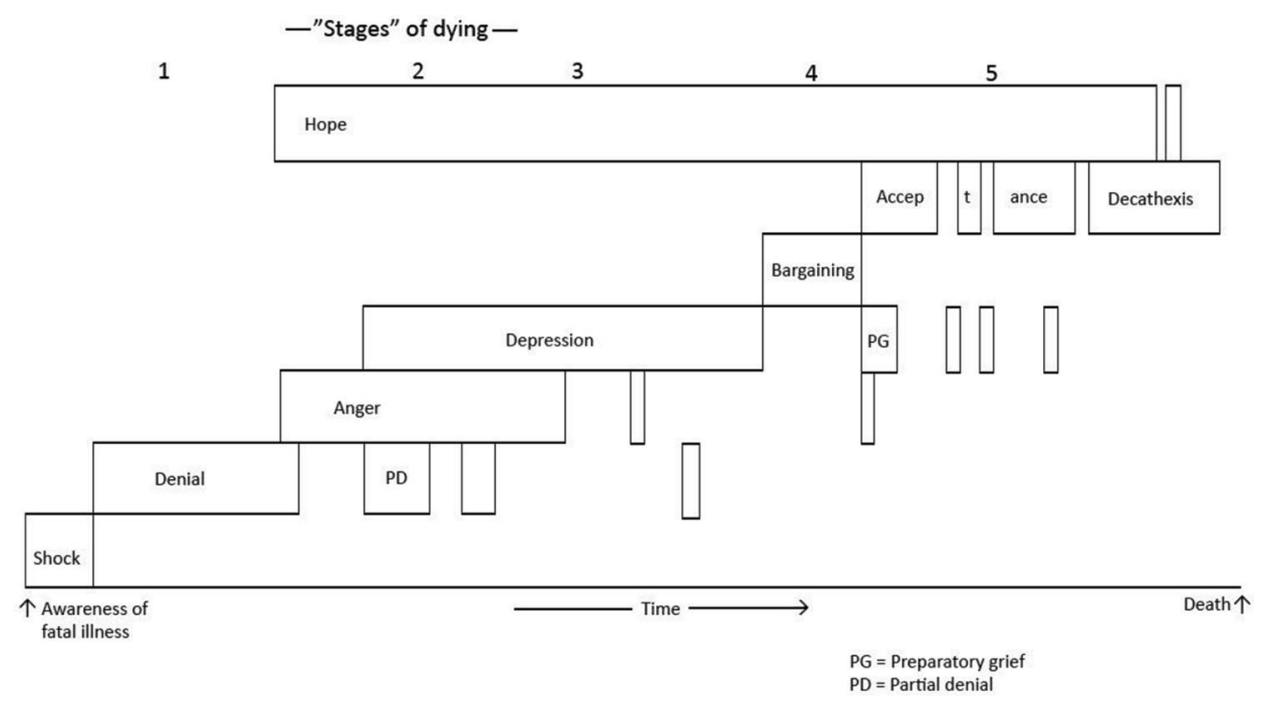

Source: Kübler-Ross (2009, p. 216). Reprinted with permission from Taylor \& Francis.

Note: For copyright reasons, we reprint the figure in its original form as it appeared in both editions of the book (1969, p. 235; 2009, p. 216). However, we want to point out that a mistake was made when depicting 'Depression' as Stage 3 and 'Bargaining' as Stage 4. In the structure of the book, these chapters come in the reversed order, their headings being 'Third Stage: Bargaining' and 'Fourth Stage: Depression', respectively. That is also the order in which we discuss the stages. 
Having found the primary source and ending our pursuit, a natural step is now to examine critically this source and the way in which management theorists employ it in their approach to organizational changes.

\section{Criticism of the source I (Kübler-Ross)}

Kübler-Ross (2009) developed her model (Figure 1) on the basis of an analysis of interviews with more than 200 patients who had been informed that they were terminally ill. The interviews concerned their reactions to the inevitability of death. The figure's time axis starts with the patient becoming aware that he or she has an incurable and deadly disease, which leads to a shock (2009, pp. 213-214): 'All of our patients reacted to the bad news in almost identical ways [...] namely with shock and disbelief'. This is a starting point that can lead into the various stages, which are as follows: 1 ) Denial, 2) Anger, 3) Bargaining, 4) Depression and 5) Acceptance, and, in addition, Decathexis. From the second stage onwards, another dimension - Hope - runs in parallel to the other stages. In her discussion, a certain logic emerges between the stages (Chapters 3-7). The first stage of denial of a terminal disease cannot be sustained in the long run, but transitions into disease awareness, at which point anger that I should suffer this fate kicks in. This in turn can be replaced by a phase of bargaining, in which the patient thinks he or she can avoid death by doing good deeds. Here, Kübler-Ross talks a lot about trying to persuade god. A feeling of helplessness, leading to depression, can follow this. Finally, there is a stage of passive acceptance of the realization that I will very soon die.

Thus, the model expresses empirical stages in the form of events rather than underlying mechanisms. When Kübler-Ross accounts for the content of the various stages, she does so by means of detailed descriptions - sometimes involving several uninterrupted pages of transcripts from the interviews - of individual cases in combination with advice from the various professionals involved (doctors, nurses and priests) and from relatives about how the patient should be dealt with at a given stage. The explanations of patient reactions are not attributed to mechanisms in the stages themselves, but rather to psychological factors for each individual, as for example 'She was full of anger and resentment, which seemed to originate in her early childhood' (2009, p. 63) and 'Another problem patient is the man who has been in control all his life and who reacts with rage and anger when he is forced to give up these controls' (2009, pp. 43-44). It is worth noticing that this is the first time in our pursuit that we come across an analysis based on substantiated and cited data.

If we return to Kübler-Ross's model (Figure 1), we notice that she does not explicitly say why she puts quotation marks around the term 'stages' in the figure's heading. However, one likely interpretation is that she wants to indicate that they are not to be regarded as deterministically sequential. This interpretation is supported by several statements she makes on the matter, for example 'These means [stages] will last for different periods of time and will replace each other or exist at times side by side' (2009, p. 112), or, 'The diagram [our Figure 1 ...] demonstrates how these stages do not replace each other but can exist next to each other and overlap at times' (2009, p. 214). The aforementioned Imara, who was one of her collaborators, has also emphasized this characteristic of the model (1975, p. 160):

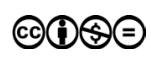


Some people got stuck at one stage $[. .$.$] and seemed to remain there until death. Some$ people were stuck at one place and then began to move toward resolution after a period of time. Other people seemed to move through the five stages relatively smoothly with very little intervention or support on the part of the staff.

This characteristic is also emphasized by Allan Kellehear (2009) in his introduction to the edition of the book published on the occasion of its 40th anniversary. Here, he writes (p. ix):

The so-called 'stage-theory' that you will read in this book is openly described and discussed as a heuristic device. In other words, these stages are merely a set of categories artificially isolated and separately described so that the author can discuss each of these experiences more clearly and simply.

In our opinion, Kübler-Ross's model and the reasoning surrounding it constitute a sophisticated empirical analysis of a very rich data material. It has also had great practical influence on the treatment of dying patients. For example, one commentator (Foskett 2001, p. 349) says: Kübler-Ross's 'research into death and dying gave a voice to the patient which has revolutionized most forms of care in this field'. And another (Kellehear 2009, p. vii) argues that the book is 'one of the most important humanitarian works on the care of dying written in the Western world'.

Only on one point do we have serious critique to level at this source: Kübler-Ross argues that the stages in the figure can also be related to other events in people's lives. She states (1975, p. 145): 'The stages of dying that I have described apply equally to any significant change (e.g., retirement, moving to a new city, changing jobs, divorce) in a person's life'. However, in this discursive recontextualization of her model, she does not provide any evidence for this claim and it should therefore not be seen as acceptable in a scientific context. Our doubts are only deepened by the fact that the actions referred to in the given examples can be voluntary: You could have decided for yourself when you wanted to retire, you may have decided yourself to move to another city or change jobs - and you might have been the one who took the initiative to have a divorce. However, you did not decide to become terminally ill and you cannot influence the inevitability of death. In the events given in her examples, the premise of shock or the first stage of denial do not occur, insofar as they are voluntary, and thus the subsequent stages do not occur either. Her empirical generalization therefore lacks legitimacy. From a discourse theory perspective, they are instead ideological in a striving to universalize the model.

\section{Criticism of the source II (management researchers on organizational changes)}

Let us start with a conceptual suggestion. In principle, we can make the following distinctions of discourses in the literature concerning organizational change, defined by their discursive perspective and their research questions: Management theorists are writers who start from a management perspective and ask the question 'How can management carry out organizational changes?'; consequence theorists who start from the 
perspective of the other employees, whereby they ask the question 'What consequences do organizational changes have for the employees and how do they react?'; relational theorists start from neither of these two perspectives, but rather ask the question 'What are relations between management and other employees like in the event of organizational changes?'. Management theorist, consequence theorist and relational theorist are different types of agents in diverse social positions in the structure of social science. Their respective type of analysis may overlap, but the writers that take Kübler-Ross's model of " "Stages" of Dying' and apply it to 'resistance to change' belong unequivocally to the management theorists and a discourse based on management ideology.

The Kübler-Ross model has had enormous influence on management researchers who also deal with the reactions of employees to organizational changes (for an overview, see Elrod \& Tippett 2002). However, those writers who uncritically apply the " "Stages" of dying' model to a range of circumstances in organizations ought to be a good deal more critical to their sources, since there is no evidence for this empirical generalization. The extent of these generalizations emerges not least in the terms that turn up in the $\mathrm{Y}$-axis (the $\mathrm{X}$-axis being invariably time). Here is a random selection: Impact on the organization (Jones \& Recardo 2013), Feelings/competence (Orridge 2009), Morale and competence in teams (Goodman \& Loh 2011), Motivation (Mitchell et al. 2019) or simply Organizational change (Daugird \& Spencer 1996). Irrespective of the variable on the Y-axis, a common feature of most of them is that they present the Kübler-Ross model as deterministically sequential. Here is an example (Wiggins 2009, p. 20): 'Kübler-Ross found that the cycle of emotions was highly consistent: all individuals emerged from the low point to eventual acceptance of the situation'. Need we point out that this is a distortion of Kübler-Ross's own treatment of the stages, forming a discursive management ideology claiming that employees always go through the same stages in cases of organizational change, finally accepting and consenting to them?

Moreover, it is precisely the assumption concerning employees that shock and grief always follow every change, whatever the content, that those analysts applying the Kübler-Ross model as a curve showing the reactions to organizational changes have in common. This is the case regardless of whether the change is 'a pleasant one, like being promoted, or an unpleasant one, like divorce' (Orridge 2009, p. 5). Shock is also often the first stage (e.g., Orridge 2009, p. 5; Goodman \& Loh 2011, p. 244; Jones \& Recarda 2013, p. 202), in contrast to what is the case in Kübler-Ross's own model. It is thereby emphasized that employees always react in this fashion when faced with organizational change. However, this premise - expressed in the term 'resistance to change' - is highly questionable. To discuss this, let us return to where our pursuit began: the heading 'Resistance to change' in Jacobsen and Thorsvik's textbook in organization theory (2019, p. 378). Outside of management theories, this concept is often criticized, as we have already exemplified. From a discourse analytical perspective, this criticism relates to the fact that 'particular structurings of the relationships between words and the relationships between the meanings of a word are forms of hegemony' (Fairclough 1992, p. 77). The bias behind the term 'resistance to change' lies in the idea that management always take rational decisions about changes that are necessary for the organization, while workers react irrationally and emotionally with fear and resist all types of change (Karlsson 2012, pp. 15-16). This way the concept 'resistance to change' works ideologically to reinforce a management discourse on changes in organizations. The fact that the concept is empirically false has been known by interested researchers for more than

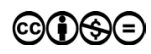


a century as a result of what is probably one of the biggest organizational changes that have ever been carried out: In 1914, Henry Ford raised workers' wages from \$2.34 to $\$ 5$ a day while at the same time reducing the working day to 8 hours. No anxiety or fear could be observed among these workers. It was an enormous organizational change: wages more than doubled in combination with shorter working hours. But it was greeted with joy and enthusiasm by the workers, not with shock, grief and angst. Thus, we have known for a considerable time that it is not change in itself that can lead to resistance, but the content of the change. Resistance arises first when those it impacts on feel threatened by the change.

Furthermore, we can observe that the stage called acceptance has a completely different meaning for Kübler-Ross than the one given in the management theorists' discourses. What she stresses is this (1992, p. 114, our emphasis):

Acceptance should not be mistaken for a happy stage. It is almost void of feelings. It is as if the pain had gone, the struggle is over, and there comes a time for 'the final rest before the long journey' as one patient phrased it.

Her description of this stage is a long way from the commitment to the new organization and the new way of working that the management theorists ideologically depict. Here are some examples: 'Acceptance is a stage at which losses due to organizational change are accepted and people let go of past realities so that they are ready to move on' (Myers et al. 2012, p. 72).

/T/here is a letting go of the past. We may say or think: "OK, here I am now, here is what I have; here is what I want". As we accept this, our feelings begin to rise and we start to become more optimistic about the situation. (Orridge 2009, p. 7)

In our last example, the final stage has been divided into two (Goodman \& Loh 2011, p. 244): 'Decision. Learning how to work in the new situation; feeling more positive. Integration. Changes integrated; a renewed individual'. The examples illustrate the difficulties of making these sorts of discursive generalizations on the basis of Kübler-Ross's diagram and reasoning. In her model, acceptance means passive resignation, or even a lack of emotion. The management theorists, on the other hand, are trying to emphasize that resistance to organizational change will be conquered during the course of the different stages. Therefore, the term acceptance acquires quite different connotations of possibilities, letting go (of resistance), consent, optimism and integration in the changes than those found in the source they cite. In spite of these distortions, the diagrams are labeled 'Kübler-Ross transition curve' and 'Kübler-Ross change curve', respectively. Now, her model does not take the form of a curve, but more important is that it is clear that the authors intend the development of the stages to ideologically conclude with a completely different meaning to the one it is assigned by Kübler-Ross. For them, the term means that the employees have accepted the organizational changes, have gotten over their irrational fear and confidently - enthusiastically, even - embrace the organizational change. In this recontextualization, the work of Kübler-Ross is taken out of its context and inserted into a new context. The result is that Kübler-Ross's model is flattened and distorted without the management authors letting on about it, but still using her fame to present their case as hegemonic. 
Finally, we can observe that the 'hope' dimension has disappeared from the reasoning. Few of the authors we have examined (for an exception, see Kerney \& Hyle 2015) have mentioned this dimension, and none of those that failed to do so have explained why they excluded it. A likely explanation from a discursive perspective is, however, that this would clash conspicuously with their message that the stages end with employees adjusting to and accepting the organizational change. Were 'hope' to be introduced as a dimension running through all the stages, it would have to represent a wish that this illfated change would cease, that things would return to how they were before the change was implemented. It would be a hope that the organizational change that threatened employees would be eliminated. And that would be completely counter to the intent of these authors.

\section{Conclusion}

We became curious of the kind of studies made in the reference pursuit genre. It meant following a chain of secondary sources back to the primary source. We took as our point of departure a citation on employees 'resistance to change' from a leading Scandinavian textbook on organization theory. The reason we chose this concept is that it is one of the most contested concepts in organization theory. We therefore formulated the purpose of the article as:

/T/o apply the method of the genre of studying chains of references to an instance of a secondary source of the contested concept of resistance to change back to the primary source and thereby exercise criticism of the sources. This includes discussing whether the theory itself is empirically sustainable or sufficiently scientifically grounded.

We have interpreted the variations of argumentation in our pursuit of sources through the theoretical lens of Critical Realist Discourse Analysis. The main reason is that this theory is sensitive to the importance of the influence of nondiscursive social positions on discourses. Concepts in this theory that we use in the analysis are ideology as a means of creating consent, referring, universalizing, recontextualization and hegemony and domination.

In summary, we can observe that both the number of phases in the change processes, the descriptions of the phases and the form of the diagrams vary. The pursuit of the primary source of the stages in change processes has led us on somewhat winding paths, as we demonstrate in Figure 2. Jacobsen and Thorsvik (2019) refer to Irgens (2011). Irgens in turn refers to Hayes (2002), who refers to Hopson and Adams (1976). They in turn refer to Adams's (1969) unpublished doctoral thesis and to likewise unpublished consultant reports from workshops. Hopson and Adams (1976) refer to Imara (1975), who refers to Kübler-Ross (1969). In addition, we see that Hayes (2018) refers to Hayes and Hyde (1996) - and Hayes (2002) and Hayes (2018) are two editions of the same book. In this connection, we can note that only KüblerRoss (2009) On Death and Dying is a primary source. Since unpublished works cannot be counted, it is only this book that contains reported data as the basis for the analysis. 
Figure 2 Overview of source references.

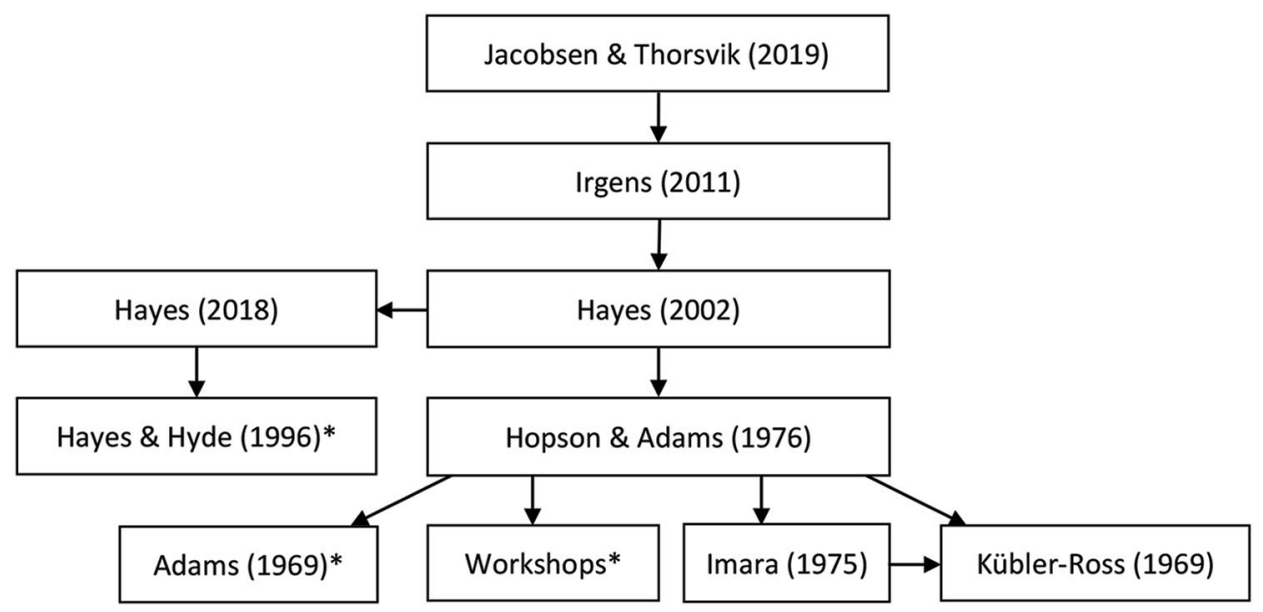

Note: Sources that are not available to us because they are unpublished are marked with an asterisk.

Having charted the chain of references, the next step was to examine critically the primary source, that is to say Kübler-Ross, and the way her model is treated in the secondary literature about organizational changes. Kübler-Ross's analysis is generally well respected in healthcare and still enjoys high status there. We concur in this positive evaluation in that context, but are critical towards her generalizing and contextualizing claim that the model is valid also for other changes in people's lives. None of the adjustments she mentions bears comparison with the inevitability of death, since they can be voluntary.

The management theorists who apply Kübler-Ross's model to organizational changes make just such a recontextualization. Their argument for doing so lies in the term they use in this context: resistance to change. The term implies that employees below management level always react irrationally with grief and fear when faced with change. The argument is empirically false, but it leads to interpretations of the model that differ greatly from those made by Kübler-Ross herself. The concept 'resistance to change' is thereby part of an ideological management discourse on organizational change. By drawing on the work of Kübler-Ross, the theory that employees go through specific phases when met with changes in organizations and that some phases involve resistance to change, is legitimized. The management ideology embedded in the concept 'resistance to change' is most effective when it becomes 'naturalized, and achieve the status of "common sense"' (Fairclough 1992, p. 87). Therefore, the recontextualization of the theory also legitimizes a wider discourse of a management ideology seeking dominance. Pursuing the trail of references may not only be a work of understanding the use of references, but also a work of understanding how management ideology permeates introductive literature on organization theory. It is hardly an exaggeration to say that among some management theorists and organizational consultants, academic urban legends (Rekdal 2014b) flourish about the painless transfer of an analysis of the way people face death's inevitability to the way employees look at organizational change. In introductory organization theory books like those presented in this article, students learn that managers need to lead employees through different phases of change to overcome 
resistance to change. The least we can ask is that they should be made aware that this is the position and perspective of a management ideology.

Our pursuit of the source led to critique of the source itself and, above all, of the way management theorists use it in their descriptions and analyses of employees' reactions to organizational change. The originality of the analysis lies in the combination of its two contributions. One is that it contributes to the genre of reference pursuit by developing its field of research. So far, it has mainly studied variations in descriptions of empirical patterns. However, our study shows that the methodology can also be applied to investigating discrepancies in theoretical argumentation. The research field of the genre has thereby been enlarged. The other contribution is to social science criticism of the contested concept of resistance to change. It has been critiqued in the organization theory literature, but it has not earlier been scrutinized in the way we do here. Through the pursuit of the primary source, we have been able to point out the ideological way management theorists have handled Kübler-Ross's model through recontextualizing it to the discourse of resistance to change. We thereby present an original conceptual analysis.

\section{References}

Adams, John (1969). Phases of personal and professional development. (Unpublished doctor's dissertation.) Cleveland, Ohio: Case Western Reserve University.

Adams, John, John Hayes \& Barrie Hopson (1976). Introduction, p. ix-xiii in John Adams, John Hayes \& Barrie Hopson (1976) Transition: Understanding and managing personal change, London: Martin Robertson.

Peter Campbell, Tamsin Cox \& Dave O'Brien (2017). The social life of measurement: how methods have shaped the idea of culture in urban regeneration, Journal of Cultural Economy 10(1): 49-62. doi: https://doi.org/10.1080/17530350.2016.1248474.

Choi, Myungweon \& Wendy E. A. Ruona (2010). Individual readiness for organizational change and its implications for human resource and organization development, Human Resource Development Review 10(1): 46-73.

Coch, Lester \& Johan R. P. French (1948). Overcoming resistance to change, Human Relations 1(4): 512-532. doi: https://doi.org/10.1177/001872674800100408.

Danermark, Berth, Mats Ekström \& Jan Ch. Karlsson (2019, 2. ed.). Explaining Society. Critical Realism in the Social Sciences, London: Routledge.

Daugird, Allen \& Donald Spencer (1996). Physician reactions to the health care revolution. A grief model approach, Archives of Family Medicine 5: 497-500.

Dent, Erik B. \& Susan Galloway Goldberg (1999). Challenging 'resistance to change.' Journal of Applied Social Science 35(1): 25-41.

Elrod, P. David \& Donald D. Tippett (2002). The 'death valley' of change, Journal of OrganizationalChange Management 15(3):273-291.doi: https://doi.org/10.1108/095348 10210429309.

Fairclough, Norman (1989). Language and Power, Harlow: Longman.

Fairclough, Norman (1992). Discourse and Social Change, Cambridge: Polity Press.

Fairclough, Norman (2003). Analysing Discourse: Textual analysis for Social Research, New York: Routledge.

Fairclough, Norman (2005). Peripheral vision: discourse analysis in organization studies: the case for critical realism, Organization Studies 26(6): 915-939. doi: https://doi.org/ $10.1177 / 0170840605054610$. 
Fairclough, Norman (2009). A dialectical-relational approach to critical discourse analysis in social research, pp. 162-186 in Ruth Wodak \& Michael Meyer (Eds.), Methods of Critical Discourse Analysis (2. ed.), London: Sage.

Fairclough, Norman, Bob Jessop and Andrew Sayer (2002). Critical realism and semiosis, Alethia 5(1): 2-10. doi: https://doi.org/10.1558/aleth.v5i1.2.

Fleetwood, Steve (2004). An ontology for organization and management studies, pp. 27-53 in Steve Fleetwood and Stephen Ackroyd (eds) Critical Realism Applications in organization and management studies, London: Routledge.

Fleetwood, Steve (2005). Ontology in organization and management studies: a critical realist perspective, Organization 12(2): 197-222.

Foskett, John (2001). What of the clients-eye view? A response to the millennium review, British Journal of Guidance \& Councelling 29(3):345-350.doi: https://doi.org/10.1080/0306988 $\underline{0120073058 .}$.

Goodman, Elisabeth \& Lucy Loh (2011). Organizational change: a critical challenge for team effectiveness, Business Information Review 28(4): 242-250. doi: https://doi.org/10.1177/ 0266382111427087.

Gravetter, Frederick J. \& Lori-Ann B. Forzano (2012). Research Methods for the Behavioral Sciences, Belmont, CA: Wadsworth.

Harzing, Anne-Wil (2002). Are our referencing errors undermining our scholarship and credibility? The case of expatriate failure rates, Journal of Organizational Behavior 23(1): 127-148.

Hayes, John (2002). The Theory and Practice of Change Management, Basingstoke: Palgrave.

Hayes, John (2018). The Theory and Practice of Change Management, Basingstoke: Palgrave. doi: https://doi.org/10.1057/978-1-352-00132-7.

Hayes, John \& Peter Hyde (1996). Transitions workshop. (Unpublished manual.), Reading: Hyde Management Consulting.

Hopson, Barrie \& John Adams (1976). Towards an understanding of transition: Defining some boundaries of transition dynamics, pp. 3-25 in John Adams, John Hayes \& Barrie Hopson (1976, eds) Transition: Understanding and managing personal change, London: Martin Robertson.

Huzell, Henrietta (2005). Management och motstånd. Offentlig sektor i omvandling - en fallstudie. (Management and resistance. Public sector in transformation - a case study.), Karlstad: Karlstad University Press.

Imara, Mwalimu (1975). Dying as the last stage of growth, pp. 147-163 in Elisabeth Kübler-Ross (ed.) Death: the final stage of growth. Englewood Cliffs: Prentice-Hall.

Irgens, Eirik J. (2011). Dynamiske og lærende organisasjoner: Ledelse og utvikling i et arbeidsliv i endring. (Dynamic and learning organizations: Leadership and development in a changing working life.) Bergen: Fagboksforlaget.

Jacobsen, Dag Ingvar \& Jan Thorsvik (2019). Hvordan organisasjoner fungerer. (How Organizations Work.), Bergen: Fagbokforlaget.

Jones, David J. \& Ronald J. Recarda (2013). Leading and Implementing Business Change Management. Making Change Stick in the Contemporary Organization, London: Routledge. doi: https://doi.org/10.4324/9780203073957.

Karlsson, Jan Ch. (2012). Organizational Misbehavior in the Workplace. Narratives of Dignity and Resistance, Basingstoke: Palgrave Macmillan.

Karlsson, Jan Ch. \& Ann Bergman (2012). Methods for Social Theory. Analytical Tools for Theorizing and Writing, London: Routledge.

Kearney, Kerri S. \& Adrienne E. Hyle (2015). A look through the Kubler-Ross theoretical lens, pp. 109-128 in Vincent A. Anfara \& Norma J. Mertz (eds) Theoretical Frameworks in Qualitative Research, Thousand Oaks: Sage. 
Kellehear, Allan (2009). Introduction, pp. vii-xviii in Elisabeth Kübler-Ross (ed.) On death and dying: What the dying has to teach doctors, nurses, clergy and their own families, Oxon: Routledge.

Kübler-Ross, Elisabeth (1969). On death and dying. What the dying have to teach doctors, nurses, clergy and their own families, New York: Macmillan.

Kübler-Ross, Elisabeth (1975). Death: the final stage of growth, p. 145 in Elisabeth Kübler-Ross (ed.) Death. The final stage of growth, Englewood Cliffs: Prentice-Hall.

Kübler-Ross, Elisabeth (2009 [1969]). On death and dying: What the dying has to teach doctors, nurses, clergy and their own families, Oxon: Routledge.

Lewin, Kurt (1951). Field theory in social science: selected theoretical papers (Edited by Dorwin Cartwright.), New York: Harper \& Row.

Mitchell, Deb, Lisa O’Brien, Anne Bardoel \& Terry Haines (2019). Understanding health professional responses to service disinvestment: a qualitative study, International Journal of Health Policy Management 8(7): 403-411. doi: https://doi.org/10.15171/ijhpm.2019.20.

Morrisey, Locke J. (2002). Bibliometric and bibliographical analysis in an era of electronic scholarly communication, Science \& Technology Libraries 22(3-4): 149-160.

Myers, Piers, Sally Hulks \& Liz Wiggins (2012). Organizational change. Perspectives on theory and practice, Oxford: Oxford University Press.

Newman, Jack (2020). Critical realism, critical discourse analysis, and the morphogenetic approach, Journal of Critical Realism (Prepublished). doi: https://doi.org/10.1080/1476 7430.2020 .1758986$.

Oreg, Shaul (2003). Resistance to change: developing an individual differences measure, Journal of Applied Psychology 88(4): 680-693. doi: https://doi.org/10.1037/0021-9010. 88.4.680.

Orridge, Martin (2009). Change leadership. Developing a change-adept organization, Farnham: Gower.

Pardo del Val, Manuela and Clara Martinez Fuentes (2003). Resistance to change: a literature review and empirical study, Management Decision 41(2): 148-155.

Rekdal, Ole Bjørn (2014a). Academic citation practice: a sinking sheep? Portal: Libraries and the Academy 14(4): 567-585. doi: https://doi.org/10.1353/pla.2014.0025.

Rekdal, Ole Bjørn (2014b). Academic urban legends, Social Studies of Science 44(4): 638-654. doi: https://doi.org/10.1177/0306312714535679.

Wiggins, Liz (2009). Managing the ups and downs of change communication. Applying theories of psychology to guide employees through the change journey, Strategic Communication Management 13(1): 20-23.

Wodak, Ruth \& Michael Meyer (2009). Methods of Critical Discourse Analysis (2. ed.), London: Sage.

Wright, Malcome \& J. Scott Armstrong (2008). The ombudsman: verification of citations: Fawlty towers of knowledge? Interfaces 38(2): 125-139.

Yilmaz, Derya and Gökhan Kiliçoğlu (2013). Resistance to change and ways of reducing resistance in educational institutions, European Journal of Research on Education 1(1): $14-21$.

Zander, Alvin (1950). Resistance to change-its analysis and prevention, Advanced Management Journal 15(1): 9-11. 